\title{
Navigating Personal and Relational Concerns: The Quest for Equilibrium
}

\author{
Madoka Kumashiro \\ Goldsmiths, University of London
}

\author{
Caryl E. Rusbult \\ Vrije Universiteit Amsterdam
}

\author{
Eli J. Finkel \\ Northwestern University
}

\begin{abstract}
The authors' personal-relational equilibrium model suggests that people come to seek equilibrium in their dedication to personal and relational concerns in that these 2 important needs cannot always be gratified simultaneously. The authors proposed that the experience of personal-relational disequilibrium motivates attempts to restore equilibrium and that achieving equilibrium promotes life satisfaction. Four studies revealed good support for the model. In Study 1, a manipulation of anticipated future disequilibrium (vs. equilibrium) as a result of overdedication to either the personal or relational domain caused reduced motivation to address concerns in that domain and increased motivation toward the complementary domain. In Study 2, narratives describing disequilibrium experiences (vs. equilibrium experiences) exhibited increased motivation to restore equilibrium and reduced life satisfaction. In Study 3, diary reports of everyday disequilibrium were associated with increased same-day motivation to restore equilibrium, reduced same-day life satisfaction, and increased next-day dedication of effort to the complementary domain. In Study 4, experiences of disequilibrium predicted reduced well-being 6 months later. Collectively, these findings extend knowledge of how people regulate themselves toward equilibrium in pursuing 2 fundamental human concerns.
\end{abstract}

Keywords: romantic relationships, needs, self-regulation, equilibrium, well-being

What does it mean to lead a meaningful life-a life characterized by fulfillment and vitality? It is a psychological truism that humans pursue personal concerns and benefit from the gratification of such concerns-people seek to gratify needs that are unique to the self, such as achievement and basic physiological needs. It is also a psychological truism that humans pursue relational concerns and benefit from the gratification of such concerns-people seek to gratify needs that are uniquely social, such as belongingness and companionship. Thus, a meaningful life might be characterized as one in which all of one's personal and relational needs are simply, harmoniously, and simultaneously gratified. Unfortunately, a third truism is that often, pursuing concerns in one domain conflicts with the ability to gratify needs in the complementary domain. Time and energy are not limitless, such that Mary cannot dedicate $10 \mathrm{hr}$ a day to enjoying quality time with John and dedicate $10 \mathrm{hr}$ a day to writing the great American novel. In the following pages, we advance a model of personal-relational equilibrium, proposing that sustaining optimal equilibrium between personal and relational concerns is an important form of self-

Madoka Kumashiro, Department of Psychology, Goldsmiths, University of London, London, England; Caryl E. Rusbult, Department of Social Psychology, Vrije Universiteit Amsterdam, Amsterdam, the Netherlands; Eli J. Finkel, Department of Psychology, Northwestern University.

Studies 3 and 4 were supported by National Science Foundation Grant BCS-0132398 to Caryl E. Rusbult and by funding from the Fetzer Institute.

Correspondence concerning this article should be addressed to Madoka Kumashiro, Department of Psychology, Goldsmiths College, University of London, Whitehead Building, New Cross SE14 6NW, London, United Kingdom. E-mail: madoka_kumashiro@yahoo.com regulation. We present findings from four studies that tested basic tenets of our model.

\section{Personal Concerns, Relational Concerns, and Subjective Well-Being}

People pursue varied goals, as documented in diverse typologies of human motivation (e.g., Deci \& Ryan, 2000; Maslow, 1968; H. A. Murray, 1938; Ryff, 1989). Among the multitude of goals that drive human behavior and enrich personal well-being, personal and relational concerns consistently are regarded as core motives. Personality theorists have argued for the centrality of personal and relational concerns using terms such as work and love (Freud, 1920) or agency and communion (Bakan, 1966), proposing that both personal and relational gratifications are crucial for a meaningful life (e.g., Deci \& Ryan, 2000; H. A. Murray, 1938; Ryff, 1989). Personal and relational concerns have been argued to exist in a hierarchy of importance (Maslow, 1968), to dominate during differing developmental stages (Erikson, 1950), or to serve as the foundation from which other needs can be pursued or gratified (Bowlby, 1969). Granted, some everyday activities cannot easily be categorized as personal or relational (e.g., cleaning the house, walking the dog). Nevertheless, personal and relational concerns arguably are core domains in understanding human motivation and life satisfaction.

In the present work, personal concerns are defined as the behaviors that humans enact for themselves, including time, effort, and resources dedicated to gratifying self-oriented needs (e.g., physiological, autonomy, competence needs) and to promoting self-oriented goals (e.g., personal goal pursuits, individual growth, 
exploration). For example, Mary's personal concerns might include professional activities, personal hobbies or pastimes, or physical fitness. The benefits of personal need fulfillment are well documented (e.g., Deci \& Ryan, 2000; Myers \& Diener, 1995). In contrast, relational concerns are defined as the behaviors that humans enact for their relationships, including time, effort, and resources dedicated to gratifying relationship-oriented needs (e.g., intimacy, companionship, sexuality needs) and to promoting relationship-oriented goals (mutual support, relationshipmaintenance activities). For example, Mary's relational concerns might include activities shared with a close partner, entertaining close friends, and sustaining good relations with family members. The benefits of relational need fulfillment are also well documented (e.g., Berkman, Leo-Summers, \& Horwitz, 1992; Uchino, Cacioppo, \& Kiecolt-Glaser, 1996).

Sometimes personal and relational needs can simply, harmoniously, and simultaneously be gratified. For example, when John pursues his favorite personal pastime by cooking a great meal for Mary's birthday, his activities may be categorized as both personal and relational. Moreover, to the extent that involvement with a partner entails strong interdependence or high levels of self-other merger, there may be considerable permeability in whether specific activities gratify personal or relational needs (e.g., Aron \& Aron, 2000; Rusbult, Kumashiro, Coolsen, \& Kirchner, 2004). For example, when Mary's pursuit of professional excellence yields rewards for both Mary and John, her professional pursuits may be categorized as both personal and relational. But sometimes, personal and relational needs cannot simply, harmoniously, and simultaneously be gratified. The pursuit of concerns in one domain may conflict with or limit the ability to pursue concerns in the complementary domain because behaviors relevant to the two domains are incompatible or because of the finite nature of time, energy, or resources (e.g., Kelley et al., 2003; Marks, 1977). For example, the many hours that John dedicates to work may leave only limited time for shared activities with Mary. ${ }^{1}$ Thus, although we might ideally wish to "have it all"- to enjoy the full gratification of both personal and relational concerns-pursuing a meaningful life may sometimes entail tradeoffs between personal and relational concerns.

\section{Personal-Relational Equilibrium Model}

We developed a model of personal-relational equilibrium to explain how people regulate tradeoffs between potentially competing classes of concern. Our model builds on work in which it is argued that (a) both personal and relational concerns are crucial to life satisfaction and (b) such concerns may not always simultaneously be pursued or gratified because of behavioral incompatibility or the finite nature of time, energy, or resources (e.g., Deci \& Ryan, 2000; Marks, 1977; Ryff, 1989; Sheldon \& Niemiec, 2006). Our model employs key concepts of homeostasis theory (Cannon, 1920; Stagner, 1951), using principles of equilibrium that have been shown to serve as a useful metaphor for understanding diverse psychological processes (e.g., Carver \& Scheier, 1998; Hazan \& Shaver, 1994; O'Connor \& Rosenblood, 1996).

We suggest that, as a consequence of continually attempting to maximize personal and relational need fulfillment under conditions of finite time and resources, people develop adaptationsthey acquire regulation strategies that tend to yield at least mod-
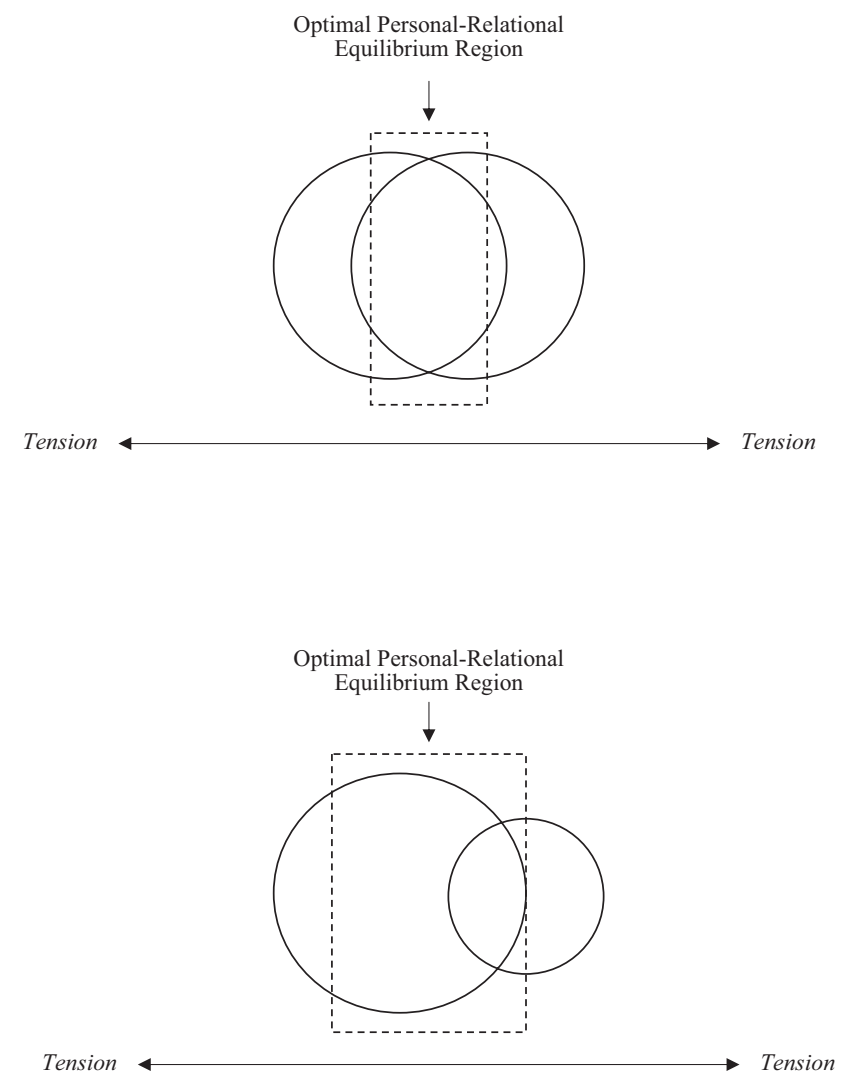

Figure 1. Optimal personal-relational equilibrium standards. A: Optimal personal-relational equilibrium-50/50 weighting of concerns, high compatibility of domains, high sensitivity to disequilibrium. B: Optimal personal-relational equilibrium-65/35 weighting of concerns, low compatibility of domains, low sensitivity to disequilibrium.

erate gratification of their needs. In recognition of the fact that personal-relational tradeoffs often are necessary, people learn that equilibrium is important and desirable and develop optimal standards of dedication to their personal and relational concerns. As illustrated in Figure 1, an optimal equilibrium standard describes the relative tradeoff of concerns that a given individual experiences as comfortable. Equilibrium standards presumably vary on at least three dimensions: (a) relative importance of the personal and relational domains-whether the optimal equilibrium region is centered on $50 / 50$ or some other relative dedication to the two domains (see Figure 1, variations in size of circles); (b) relative compatibility of domains, or the extent to which specific activities simultaneously gratify the two domains (see Figure 1, variations in overlap of circles); and (c) sensitivity to disequilibrium-in the range of tradeoffs that a given individual experiences as acceptable (see Figure 1, variations in breadth of optimal equilibrium region). For example, Figure 1A represents a person for whom personal and relational concerns are equally important (circles are equal in

\footnotetext{
${ }^{1}$ Note that pursuits are classified in terms of the needs they ultimately gratify, not in terms of their concrete properties. For example, if Mary works at an unfulfilling job to support John's medical education, her work activities may be categorized as primarily relational, rather than personal.
} 


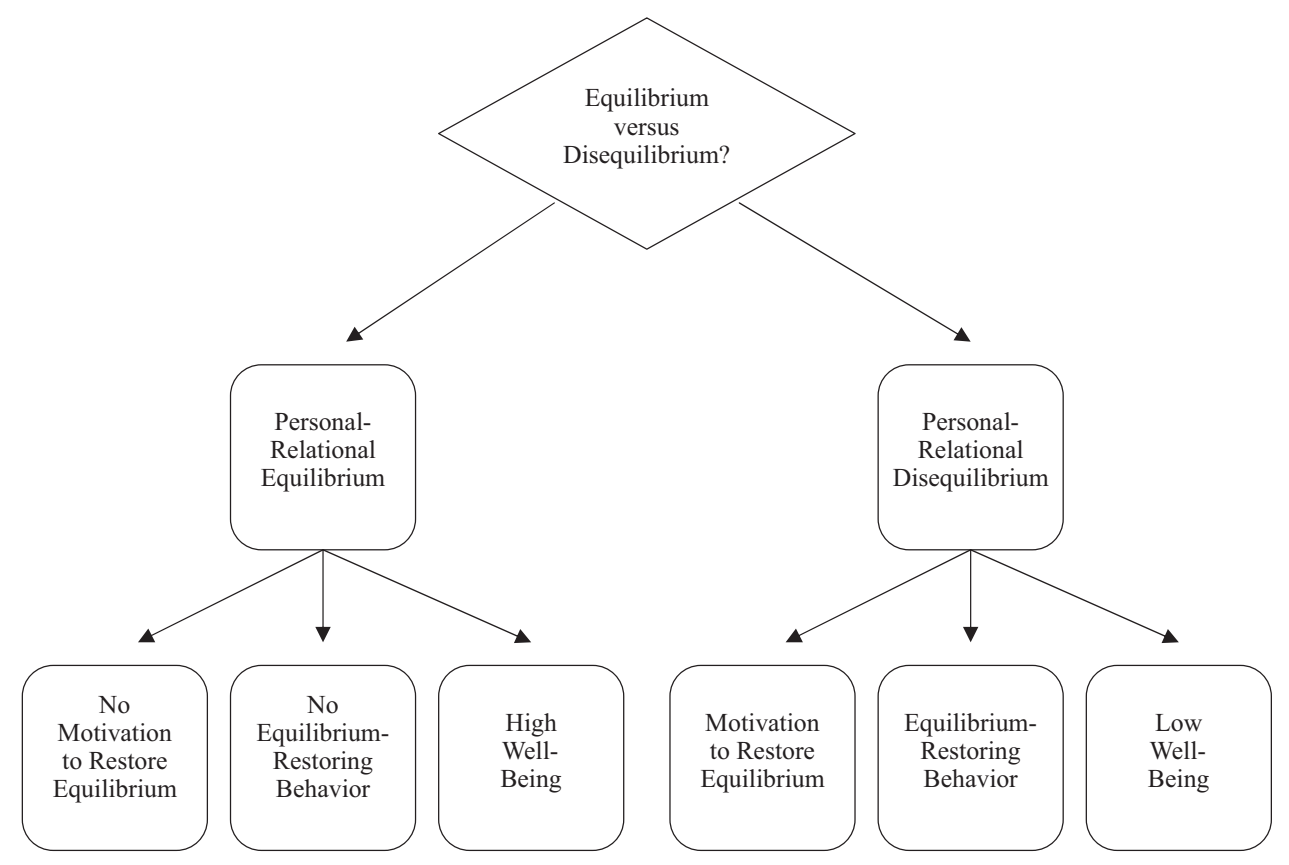

Figure 2. Personal-relational equilibrium model.

size), for whom the two domains frequently are compatible (circles overlap greatly), and for whom even minor departures from equilibrium yield tension (equilibrium region is narrow). In contrast, Figure 1B represents a person for whom personal concerns are more important than relational concerns, for whom the two domains frequently are incompatible, and for whom moderate departures from equilibrium are acceptable. ${ }^{2}$ The present work examines the process and outcomes of equilibrium seeking, not the character or origin of optimal equilibrium standards per se. However, we assume that optimal standards (a) are influenced by biological makeup and developmental histories, (b) are embodied in personal dispositions but are also shaped by situational variables, (c) may be implicit or consciously articulated, and (d) may change over brief or extended periods of time.

Homeostasis describes a process whereby a system sustains equilibrium by means of dynamic adjustments controlled by interrelated regulation mechanisms. Tension is experienced when a system deviates from its optimal equilibrium standard. The corrective actions necessary to restore equilibrium may entail either automatic processes (e.g., sweating to cool an overheated body) or controlled processes (e.g., wearing warm clothes during the winter). In parallel manner, our personal-relational equilibrium model suggests that people are motivated to maintain equilibrium between personal and relational concerns. Mary will feel comfortable so long as her everyday activities and experiences remain within her equilibrium region. Of course, dedicating time and effort to each domain does not guarantee that each need will be maximally gratified (e.g., we may invest in failing enterprises), nor are accrued benefits necessarily immediate (e.g., need gratification may rest on temporally extended investments). But because Mary's equilibrium region represents an adaptation-based comfort zone, in which her personal and relational needs have been reasonably well gratified, equilibrium is experienced as desirable.
Of course, it is difficult to remain permanently within one's equilibrium region. Most people at times depart from equilibrium-specific activities may necessitate exceptionally high dedication of time and resources, external demands or obligations may require one's attention, or opportunities may become available that seduce one into departing from equilibrium. When people depart from optimal equilibrium by dedicating high levels of time, effort, or resources to one domain at the expense of the complementary domain, they experience tension. Tension takes the form of motivation to restore equilibrium, along with changes in behavior oriented toward restoring equilibrium (see Figure 2). Equilibriumseeking motivation and behavior entail not only (a) increased dedication to the neglected, underdedicated domain but also (b) reduced dedication to the complementary, overdedicated domain. For example, Mary may realize that she has not done much writing lately because of the many hours she has enjoyed dining out with John. She will experience tension and will consciously or unconsciously become motivated to dedicate increased time to her writing. In turn, if she spends an inordinate amount of time on her career or other personal concerns, she may once again experience disequilibrium and set aside a weekend to spend time with John. This frequently nonconscious process will proceed as Mary strives to sustain an optimal equilibrium between her personal and relational concerns.

We suggest that when people successfully regulate their activities in such a manner as to sustain equilibrium, they experience

\footnotetext{
${ }^{2}$ Note that equilibrium does not imply 50/50 dedication to the two domains. Just as a scale may be balanced for $60 / 40$ weights if the fulcrum is to the left of center, an individual may seek equilibrium around a set point with differential importance weightings for personal and relational concerns.
} 
enhanced well-being (see Figure 2). Why so? People have powerful needs in the personal and the relational domains, including not only personal needs, such as autonomy and competence (e.g., Deci \& Ryan, 2000; Ryff, 1989), but also relational needs, such as belongingness and closeness (e.g., Aron \& Aron, 2000; Baumeister \& Leary, 1995). However, irrespective of the importance of a given concern, fulfillment in one domain cannot compensate for the absence of fulfillment in another domain. Thus, people are likely to enjoy maximum well-being to the extent that they sustain equilibrium, (a) engaging in activities that simultaneously gratify the two domains or (b) exhibiting efficient temporal shifts in dedication to the two domains. ${ }^{3}$ When we fail to sustain equilibrium-when we neglect one domain at the expense of another or are unable to efficiently shift from one to the other-the accompanying aversive motivational state can take its toll in the form of reduced psychological or physical well-being (cf. McEwen, 1998). Thus, life satisfaction and other forms of personal well-being should be enhanced when people sustain equilibrium not only over the course of a given day but also over more extended periods of time. Indeed, the extant literatures on work-versus-family conflicts and caregiving conflicts provide indirect support for this claim, demonstrating the short- and long-term benefits of balance (e.g., Adams, King, \& King, 1996; Sheldon \& Niemiec, 2006; Stephens \& Franks, 1999).

Does equilibrium also influence relational well-being? Whereas it seems clear that dedicating high effort to the personal domain at the expense of the relational domain is unlikely to promote relational well-being, it is less clear that dedicating high effort to the relational domain at the expense of the personal domain necessarily will harm relational well-being (i.e., why would ever-greater dedication to the relational domain harm relationships?). We suggest that relationships, too, are harmed by disequilibrium - that relationships function poorly not only (a) when relational needs are neglected but also (b) when relational needs are promoted at the expense of important personal needs, such as autonomy, selfexpansion, or movement toward the ideal self (Aron \& Aron, 2000; Deci, La Guardia, Moller, Scheiner, \& Ryan, 2006; Drigotas, Rusbult, Wieselquist, \& Whitton, 1999). Therefore, we suggest that deviations from equilibrium also yield reduced relational well-being.

\section{Hypotheses and Research Overview}

Thus, our model predicts that people are motivated to maintain an optimal equilibrium between their personal and relational concerns. When people become aware of disequilibrium, they experience tension and are motivated to shift their dedication of time and effort from one domain to the other. Consequently, experiencing underdedication to personal concerns motivates increased dedication of time, effort, and resources to the personal domain, as well as reduced dedication to the relational domain. And experiencing underdedication to relational concerns motivates increased dedication of time, effort, and resources to that domain, as well as reduced dedication to the complementary domain. Moreover, borrowing from the principles of homeostasis, we assume that tension is experienced and equilibrium seeking is motivated not only in response to present experiences of disequilibrium but also in anticipation of future disequilibrium (e.g., Stagner, 1951). In addition, we suggest that a meaningful life is achieved through sustaining an optimal equilibrium between personal and relational concerns and that deviations from equilibrium yield reduced personal well-being and relational well-being.

We conducted four studies to test one or more of these hypotheses. ${ }^{4}$ In Study 1, we employed false feedback to highlight individuals' potential for future personal disequilibrium, equilibrium, or relational disequilibrium. Later in the session, we administered measures of personal and relational motivation to assess whether the anticipation of future disequilibrium causes increased motivation toward the underdedicated domain and decreased motivation toward the overdedicated domain. Study 2 was a narrative study, designed to explore the consequences of personal-relational disequilibrium via an analysis of spontaneous, open-ended narratives describing prior experiences of equilibrium versus disequilibrium. Study 2 narratives were situated in a relational context: The study was framed as an examination of under- versus overimmersion in a romantic relationship. In complementary manner, Study 3 was situated in a personal context, framed as an examination of everyday personal goal pursuits. Over a 10-day period, individuals provided daily diary reports of equilibrium versus disequilibrium, personal and relational motivation, actual behaviors in the personal and relational domains, and life satisfaction. These data allowed us to test model predictions by examining day-to-day, within-person fluctuations in model variables. In Study 4, a two-wave longitudinal study, we examined whether earlier personal-relational disequilibrium predicts change over a 6-month period in diverse indices of well-being, including life satisfaction, psychological well-being, physical well-being, and relational well-being.

\section{Study 1}

In Study 1, we manipulated disequilibrium using a procedure wherein we influenced people's beliefs about their future dispositions, giving participants false feedback about their future status with respect to a fictional "interaction style" trait (cf. Twenge, Catanese, \& Baumeister, 2002). Feedback communicated that over the course of their adult lives, they would in all probability experience personal disequilibrium (high dedication to personal concerns), equilibrium (optimal level of dedication to personal and relational concerns), or relational disequilibrium (high dedication to relational concerns). In an ostensibly unrelated study, participants completed three indices of equilibrium seeking: willingness

\footnotetext{
${ }^{3}$ Does equilibrium achieved through moderate dedication to both domains yield consequences that parallel those of equilibrium achieved through extremely low or extremely high dedication to both domains? The present work addresses the question of equilibrium in dedication rather than level of dedication, but we speculate that moderate levels of dedication to each of the two domains are preferable to (a) exceptionally high dedication to each domain (e.g., stressing out by trying to have it all) and (b) exceptionally low dedication to each domain (e.g., depressive inactivity). We return to this issue later, in the General Discussion.

${ }^{4}$ In light of the assumption that there are individual differences in optimal standards, across the four studies, we employed operational definitions that implicitly calibrate equilibrium versus disequilibrium relative to the participant's subjective sense of what is optimal. For example, in Study 1, we provided false feedback that "by your late 20s, you will dedicate a lot of time and energy toward meeting your personal [relational] needs ... ," such that participants were in a position to subjectively calibrate "a lot" in light of their own optimal equilibrium standards.
} 
to sacrifice for the relationship, ideal inclusion of the partner in the self, and motivation to pursue personal goals.

Our personal-relational equilibrium model assumes that motivation is influenced not only by present disequilibrium but also by the anticipation of future disequilibrium (e.g., storing food for the winter; Stagner, 1951). Thus, we predicted that when participants anticipated personal disequilibrium, they would exhibit increased motivation toward relational concerns and reduced motivation toward personal concerns - that is, they would exhibit greater willingness to sacrifice and greater desire for merger with their partners, along with reduced motivation to pursue personal goals. In complementary manner, when participants anticipated relational disequilibrium they would exhibit increased motivation toward personal concerns and reduced motivation toward relational concerns.

\section{Method}

Participants. Participants were 178 undergraduates (115 women, 50 men, 13 who did not specify gender) who took part in the experiment in partial fulfillment of the requirements for introductory psychology courses at the University of North Carolina at Chapel Hill. The recruitment Web site indicated that to take part, it was necessary for participants to have been involved in a dating relationship of at least 1 month in duration. One to 6 individuals participated in each session; participants were seated before computers in separate cubicles. Within sessions, participants were randomly assigned to one of three experimental conditions, with approximately equal proportions of women and men across conditions. Participants were 19.12 years old on average $(S D=1.09)$, and most were Caucasian (8\% African American, 6\% Asian American, $82 \%$ Caucasian, $4 \%$ other). They had been involved with their partners for an average of 21.24 months $(S D=15.13)$, and most were involved in steady dating relationships $(6 \%$ dating casually, $12 \%$ dating regularly, $80 \%$ dating steadily, $1 \%$ engaged or married, $1 \%$ other).

Procedure. Participants were informed that they would take part in two unrelated studies. In the "first study," we asked participants to complete an instrument that was said to assess interaction style. To enhance the impression that this was a valid instrument, we included in the scale 105 face-valid items that assessed constructs such as attachment style, self-esteem, and interaction behavior (e.g., "I am very comfortable being close to my partners," "I feel that I am a person of worth, at least on an equal basis with others"; 1 = do not agree at all, $5=$ agree completely). We explained that, over time, researchers had accumulated a large database regarding this construct, noting that later in the session, participants would receive feedback about their interaction-style profiles. We also explained that later, they could request an in-depth report of their interaction-style profiles, including findings describing the lifetime experiences of people with the same style. Following a brief delay (during which we supposedly assessed each person's style), participants received information about their interaction-style profiles, which served as the manipulation of disequilibrium type (personal disequilibrium vs. equilibrium vs. relational disequilibrium).

Participants then took part in a "second study," during which they were asked to provide information about their present dating relationships and goal-pursuit activities. To reinforce the impres- sion that this portion of the session concerned an unrelated study, we designed the questionnaire to have a different appearance from materials employed in other portions of the session (e.g., different instructions, experimenter name, font type, response format). The questionnaires that participants completed included items designed to assess equilibrium-restoration motivation: willingness to sacrifice for the relationship, ideal inclusion of other in the self, and personal goal-pursuit motivation. Finally, participants completed ratings that assessed interest in receiving further information about the study $(0=$ not at all interested, $8=$ extremely interested $)$, as well as the utility of the interaction-style feedback they received earlier in the session $(0=$ not at all useful, $8=$ extremely useful $)$. To assess possible suspicion, we also asked participants to answer several open-ended questions about the purpose of the study. At the end of the session, participants were fully debriefed and thanked for their assistance.

Disequilibrium-type manipulation. Disequilibrium type was manipulated via the feedback participants received about their interaction styles. Participants were told that they had been classified as one of several types and read an excerpt regarding their type that ostensibly was from a recent article regarding interaction style. To enhance the believability of this feedback, each person's unique code number was printed at the top. Across the three conditions, information regarding participants' predicted lifetime experiences communicated personal disequilibrium (e.g., "You are the type of person who will concentrate almost exclusively on your personal needs... . Right now you may be focused on your romantic relationship, but your test results indicate that by your late 20s, you will dedicate a lot of time and energy toward meeting your personal needs. . . "), equilibrium (e.g., "You are the type of person who will concentrate on both your personal needs and the needs of your romantic relationship... . Right now you may be focused primarily on either your personal needs or relational needs, but your test results indicate that by your late 20s, you will dedicate a lot of time and energy toward meeting both your personal needs and the needs of your partner and relationship. ..."), or relational disequilibrium (e.g., "You are the type of person who will concentrate almost exclusively on the needs of your romantic relationship. ... Right now you may be focused on your personal goals and needs, but your test results indicate that by your late 20s, you will dedicate a lot of time and energy toward meeting the needs of your partner and relationship....").

Questionnaires. Our measure of willingness to sacrifice for relationship was modeled on prior work regarding sacrifice and included six items that pitted the needs of the relationship against the needs of the self (Van Lange et al., 1997; e.g., "I would be willing to give up desirable activities for the sake of my relationship"; $0=$ do not agree at all, $8=$ agree completely; $\alpha=.91$ ). We measured ideal inclusion of other in the self using the Inclusion of Other in the Self Scale (Aron, Aron, \& Smollan, 1992); out of seven Venn diagrams with varying overlap between self and partner, participants indicated which diagram best described the relationship they would ideally desire with the present partner. Our measure of personal goal-pursuit motivation was developed for the purpose of the present work. Participants were asked to review their most important personal goal pursuits (e.g., academic activities, recreational activities) and to report on their motivation to pursue each goal in circumstances wherein their goal pursuits might cause problems for the partner (e.g., partner doesn't ap- 
prove, personal pursuits conflict with the partner's goals). Participants answered six items regarding their personal motivation (e.g., "I would proceed with my goal pursuits regardless of how it might affect my relationship," "I would feel determined to achieve my goals, even if doing so created problems for our relationship"; $0=$ do not agree at all, $8=$ agree completely; $\alpha=.81$ ).

\section{Results and Discussion}

Data-analysis strategy. Preliminary two-factor analyses of variance (ANOVAs) - Disequilibrium Type (personal disequilibrium vs. equilibrium vs. relational disequilibrium) $\times$ Participant Gender (male vs. female)-performed on the three dependent measures revealed that one main effect of gender was significant (men reported greater willingness to sacrifice than did women) but that no interactions were significant. Given that gender did not significantly moderate any effects, this factor was dropped from the analyses.

Involvement and suspicion checks. As noted earlier, to assess degree of involvement in the study, we gave participants the opportunity to request further information about the project, explaining that to save on costs, we would provide the report only to people who requested it; $78 \%$ requested this information, and expressions of interest did not differ significantly across conditions. In ratings of the interaction-style study that participants provided at the end of the session, they reported that they were relatively interested in receiving further information regarding their style $(M=5.29, S D=1.66)$ and that they found the feedback to be moderately useful $(M=4.36, S D=1.79)$. Ratings of usefulness and interest in further information did not differ significantly across conditions. In the open-ended questions that we administered to assess suspicion regarding the experiment, $10 \%$ of the participants expressed some form of suspicion (e.g., suspicion that the feedback was not valid, that the two studies were actually one study). Below, we report two sets of analyses: analyses that include data for suspicious participants and analyses that exclude those data.

Key dependent variables. As can be seen in Table 1, the effect of disequilibrium type was significant for all three measures (see statistics under $F$ column). Consistent with predictions, post hoc comparisons using Tukey's Honestly Significant Difference Test revealed that means for the personal disequilibrium condition differed significantly from those for the relational disequilibrium condition; means for the equilibrium condition were intermediate. That is, when people confront the prospect of overdedication to personal concerns (personal disequilibrium), they exhibit greater orientation toward the relational domain (i.e., greater willingness to sacrifice, inclusion of other in the self) and reduced orientation toward the personal domain (i.e., reduced personal goal pursuit motivation); when they confront the prospect of overdedication to relational concerns (relational disequilibrium), they exhibit reduced orientation toward the relational domain and greater orientation toward the personal domain. Given that $10 \%$ of the participants expressed some form of suspicion, we replicated the analyses excluding data for these participants and observed parallel findings, respective $F \mathrm{~s}(2,149-155)=6.22,2.68$, and 3.40, all $p \mathrm{~s}<.09$. Thus, the results of Study 1 were consistent with predictions, suggesting that when people anticipate future disequilibrium in personal concerns relative to relational concerns, they exhibit equilibrium seeking. These findings are particularly noteworthy in light of the fact that the Study 1 manipulation varied overdedication, demonstrating that the prospect of high dedication to a given domain stimulates not only increased motivation toward the complementary, underdedicated domain but also reduced motivation toward the overdedicated domain.

\section{Study 2}

The results of Study 1 provide good support for our model: When people anticipate personal disequilibrium, they exhibit increasing motivation toward the relational domain; when people anticipate relational disequilibrium, they exhibit increasing motivation toward the personal domain. At the same time, in Study 1, participants did not experience actual disequilibrium: They confronted short-term tension about anticipated future disequilibrium. To address this limitation, we conducted Study 2, a narrative study in which we asked participants to provide open-ended descriptions of real experiences of disequilibrium or equilibrium (cf. Baumeister, Stillwell, \& Wotman, 1990). The narrative approach is a good means of studying social psychological processes in that it allows researchers to examine affective, cognitive, and motivational experiences in a manner that is not shaped or restricted by the researcher's a priori operational definitions.

Given that, in Study 1, we examined disequilibrium by manipulating overdedication to the personal and relational domains, in Study 2, we examined the experience of overdedication versus equilibrium versus underdedication in a relational context. We asked each participant to identify a period during which he or she was involved in an ongoing romantic relationship (present or past) and to identify an experience during that relationship that involved

Table 1

Impact of Disequilibrium Type on Key Dependent Variables: Study 1

\begin{tabular}{lcccc}
\hline \multicolumn{1}{c}{ Variable } & $\begin{array}{c}M \text { personal disequilibrium } \\
\text { condition } \\
(n=58)\end{array}$ & $\begin{array}{c}M \text { equilibrium } \\
\text { condition } \\
(n=61)\end{array}$ & $\begin{array}{c}M \text { relational disequilibrium } \\
\text { condition } \\
(n=59)\end{array}$ & $\begin{array}{c}\text { Partial } \\
\eta^{2}\end{array}$ \\
\hline Willingness to sacrifice for relationship & $4.04_{\mathrm{a}}$ & $3.50_{\mathrm{ab}}$ & $2.75_{\mathrm{b}}$ & $7.95^{* * *}$ \\
Ideal inclusion of other in the self & $5.24_{\mathrm{a}}$ & $4.97_{\mathrm{ab}}$ & .09 \\
Personal goal-pursuit motivation & $4.16_{\mathrm{b}}$ & $4.53_{\mathrm{ab}}$ & $4.66_{\mathrm{b}}$ & $3.97^{*}$ \\
\hline
\end{tabular}

Note. Personal disequilibrium $=$ overdedication to personal domain; relational disequilibrium $=$ overdedication to relational domain. Means with different subscripts differ significantly at $p<.05$. Degrees of freedom ranged from $(2,167)$ to $(2,174)$ (degrees of freedom varied across analyses because of missing data for some variables).

${ }^{*} p<.05{ }^{* *} p<.01$. 
personal disequilibrium, equilibrium, or relational disequilibrium. To elicit disequilibrium narratives while minimizing demand characteristics, we used the relatively neutral language of "level of immersion" in a relationship, emphasized that level of immersion has no necessary implications for relational satisfaction or life satisfaction, and asked participants to describe both positive and negative aspects of their experiences. In addition to obtaining participants' self-report ratings of their narrative descriptions, we also developed a coding scheme for trained coders to employ in rating their narratives.

We examined two components of our model, including not only the motivation to restore equilibrium (as in Study 1) but also the implications of equilibrium versus disequilibrium for overall life satisfaction. We predicted that in comparison with narratives in the equilibrium condition, those in the personal and relational disequilibrium conditions would exhibit greater motivation to restore equilibrium, as well as lower levels of life satisfaction.

\section{Method}

Participants. Participants were 76 undergraduates (32 women, 44 men) who took part in partial fulfillment of the requirements for introductory psychology courses at the University of North Carolina at Chapel Hill. The data for 7 participants were excluded from the analyses because they could not bring to mind an incident suitable for the experimental condition to which they were assigned. Participants took part in the experiment in groups ranging in size from 1 to 15 individuals, with approximately equal proportions of women and men across conditions. Within sessions, participants were randomly assigned to one of three experimental conditions. Participants were 19.14 years old on average $(S D=$ 0.83), and most were Caucasian (16\% African American, 4\% Asian American, 74\% Caucasian, 6\% other). Involvement in an ongoing dating relationship was not a prerequisite for participation, but over half of the participants $(64 \%)$ had nevertheless been involved in relationships of at least 1 month in duration. Of those who were involved, over half (59\%) elected to describe incidents involving the present partner. Participants who described incidents from the present relationship had been involved with their partners for 15.14 months on average $(S D=24.69)$. Those who described incidents from past relationships had been involved with their partners for an average of 13.59 months $(S D=12.45)$ at the time of the incidents described in their narratives.

Procedure. Participants were informed that the study concerned events in dating relationships. We asked them to bring to mind the most memorable dating relationship in which they had been involved (past or present) and to recall a time in that relationship during which they experienced personal disequilibrium (e.g., "felt not at all immersed in the relationship ... when you looked out for your personal needs"), equilibrium (e.g., "felt about right in terms of personal versus relational immersion ... when you were likely to consider both your personal needs and relationship benefits"), or relational disequilibrium (e.g., "felt too immersed in the relationship ... when you were likely to disregard your personal needs"). The instructions emphasized that level of immersion in a relationship is not necessarily linked with relational satisfaction or life satisfaction. Participants answered six openended questions about the time period: questions concerning the behaviors they enacted, positive and negative features of the ex- perience, and their thoughts and feelings about their circumstances (e.g., "Describe what you were thinking and how you were feeling during this time period," "What were the positive [negative] aspects of this relationship or this time period?", "What would you have changed?"). Participants wrote narratives of approximately the same length across the three conditions-in the personal disequilibrium, equilibrium, and relational disequilibrium conditions $(M \mathrm{~s}=121.58,142.31$, and 152.58 words, respectively; $S D \mathrm{~s}=$ 38.07 , 57.04, 50.99, respectively), $F(2,66)=2.25$, $n s$. Supplementing their open-ended narratives, participants also responded to a series of 9-point scales that assessed key dependent variables (see below). At the end of the session, participants were thoroughly debriefed and thanked for their assistance.

Questionnaires. Supplementing their open-ended narratives, participants also responded to a series of 9-point scales that assessed their motivation and satisfaction level. To assess motivation to restore equilibrium, we asked participants to report on desire for change in equilibrium level (three items; e.g., "I wanted to change my level of immersion in my relationship"; for all items, $0=d o$ not agree at all, $8=$ agree completely; $\alpha=.85$ ), desire for more personal orientation (one item; "I thought I should become less immersed in my relationship"), and desire for more relational orientation (one item; "I thought I should become more immersed in my relationship"). And to assess life satisfaction, we asked participants to report on life satisfaction (Diener, Emmons, Larsen, \& Griffin, 1985; five items; e.g., "In most ways my life was close to ideal"; $0=$ do not agree at all, $8=$ agree completely; $\alpha=.90)$ and subjective well-being during the period of the incident (Campbell, Converse, \& Rodgers, 1976; 10 items; "Describe your life by circling a number for each of the following scales"; e.g., "boringinteresting," "disappointing-rewarding"; all items were 9-point bipolar scales; $\alpha=.91$ ).

Coding of narratives. We also developed a coding scheme for use in rating participants' narratives. Three trained coders independently rated each narrative; coders were blind to experimental condition. All ratings but one were dichotomous judgments; when there were disagreements between the two primary coders, ratings from the third coder were used to break the tie (for dichotomous judgments, the two raters agreed $79 \%$ of the time [range $=73 \%$ to $83 \%$ ]; for the continuous judgment, intraclass $r=.91$ ). To assess the effectiveness of the experimental manipulation, coders assessed the presence versus absence of excessive personal orientation ("Devoted excessive attention to personal concerns, interests, and needs [e.g., job, career, or school]"; for all items, $0=$ no, $1=$ yes), equilibrium ("Exhibited 'right' amount of attention to both personal concerns and relational concerns"), and excessive relational orientation ("Devoted excessive attention to relational concerns, interests, and needs"). Coders also rated key model variables, including desire to maintain present circumstances ("Didn't want to change level of equilibrium between personal and relational concerns"; for all items, $0=n o, 1=y e s$ ), desire for more personal orientation ("Wanted to begin focusing more on personal concerns, needs, and interests"), desire for more relational orientation ("Wanted to begin focusing more on relational concerns, needs, and interests"), general satisfaction level ("Expressed happiness and satisfaction in general during the time period"), and general anxiety level ("Expressed anxiety in general during the time period"). A final coding variable (the sole nondichotomous rating) was a continuous rating of personal versus relational ori- 
Table 2

Impact of Disequilibrium Type on Key Dependent Variables: Study 2

\begin{tabular}{|c|c|c|c|c|c|c|c|}
\hline Variable & $\begin{array}{c}M \text { personal } \\
\text { disequilibrium } \\
\text { condition } \\
(n=24)\end{array}$ & $\begin{array}{c}\quad M \\
\text { equilibrium } \\
\text { condition } \\
(n=26)\end{array}$ & $\begin{array}{c}M \text { relational } \\
\text { disequilibrium } \\
\text { condition } \\
(n=19)\end{array}$ & $F$ & $x^{2}$ & $\begin{array}{c}\text { Partial } \\
\eta^{2}\end{array}$ & $\phi$ \\
\hline \multicolumn{8}{|c|}{ Motivation to restore equilibrium } \\
\hline \multicolumn{8}{|l|}{ Self-report } \\
\hline Desire change in equilibrium level & $3.78_{\mathrm{a}}$ & $1.92_{\mathrm{b}}$ & $3.68_{\mathrm{a}}$ & $7.22^{* *}$ & & .18 & \\
\hline Desire for more personal orientation & $2.67_{\mathrm{b}}^{\mathrm{a}}$ & $1.62_{\mathrm{c}}$ & $3.74_{\mathrm{a}}$ & $4.65^{*}$ & & .12 & \\
\hline Desire for more relational orientation & $4.17_{\mathrm{a}}^{\circ}$ & $2.38_{\mathrm{b}}$ & $1.63_{\mathrm{b}}^{\mathrm{a}}$ & $7.57^{* *}$ & & .19 & \\
\hline \multicolumn{8}{|l|}{ Coder ratings } \\
\hline Desire to maintain circumstances & $.21_{\mathrm{b}}$ & $.69 \mathrm{a}$ & $.16_{\mathrm{b}}$ & $17.80^{* *}$ & & .51 & \\
\hline Desire for more personal orientation & $.08_{\mathrm{b}}$ & $.08_{\mathrm{b}}$ & $.37 \mathrm{a}$ & $8.55^{*}$ & & .35 & \\
\hline Desire for more relational orientation & $.29 \mathrm{a}$ & $.04_{\mathrm{b}}$ & $.05_{\mathrm{b}}^{\mathrm{a}}$ & $8.45^{*}$ & & .35 & \\
\hline \multicolumn{8}{|c|}{ Life satisfaction } \\
\hline \multicolumn{8}{|l|}{ Self-report } \\
\hline Life satisfaction & $4.60_{b}$ & $6.19 \mathrm{a}$ & $5.07_{\mathrm{b}}$ & & $6.43^{* *}$ & & .17 \\
\hline Subjective well-being & $5.82_{\mathrm{b}}$ & $6.98_{\mathrm{a}}^{\mathrm{a}}$ & $5.92_{\mathrm{b}}$ & & $4.78^{* *}$ & & .13 \\
\hline \multicolumn{8}{|l|}{ Coder ratings } \\
\hline General satisfaction level & $.38_{\mathrm{b}}$ & $.96 \mathrm{a}$ & $.42_{\mathrm{b}}$ & & $21.90^{* *}$ & & .56 \\
\hline General anxiety level & $.38_{\mathrm{a}}$ & $.12_{\mathrm{b}}^{\mathrm{a}}$ & $.58_{\mathrm{a}}^{\circ}$ & & $10.90^{* *}$ & & .40 \\
\hline
\end{tabular}

Note. Personal disequilibrium $=$ underdedication to relational domain; relational disequilibrium $=$ overdedication to relational domain. For continuous self-report measures, one-way analyses of variance were performed, along with corresponding partial $\eta^{2}$ values; for coders' categorical ratings, chi-square tests were performed, along with corresponding Cramer's phi values. Means with different subscripts differ significantly at $p<.05$. Degrees of freedom ranged from $(2,61)$ to $(2,62)$ (degrees of freedom varied across analyses because of missing data for some variables).

${ }^{*} p<.05 .{ }^{* *} p<.01$.

entation, designed to assess the effectiveness of the experimental manipulation $(0=$ excessive personal orientation, $4=$ balance, 8 = excessive relational orientation; for this coding, we analyzed the average of the coders' ratings).

\section{Results and Discussion}

Data-analysis strategy. For continuous measures, one-way ANOVAs were performed; for categorical ratings, chi-square tests were performed. Preliminary three-factor ANOVAs-Disequilibrium Type (personal disequilibrium vs. equilibrium vs. relational disequilibrium) $\times$ Participant Gender (male vs. female) $\times$ Relationship Status (whether a narrative described a present vs. past relationship)_performed on all continuous dependent variables revealed one significant main effect of gender (men reported greater life satisfaction than did women) and no significant main effects of relationship status. No interactions with gender or with relationship status were significant. Given that gender and relationship status did not significantly moderate any effects reported below, these factors were dropped from the analyses.

Manipulation checks. A one-way ANOVA (personal disequilibrium vs. equilibrium vs. relational disequilibrium) of coders' ratings of personal versus relational orientation revealed a significant effect of disequilibrium type (respective $M \mathrm{~s}=2.17,4.89$, and 6.96; respective $S D \mathrm{~s}=1.45,1.03$, and 1.27), $F(1,63)=$ $79.19, p<.01$. Also, chi-square tests performed on coders' ratings revealed that narratives in the personal disequilibrium condition were most likely to exhibit excessive personal orientation $(M \mathrm{~s}=$ $.50, .00$, and .00 , respectively), narratives in the equilibrium condition were most likely to exhibit equilibrium $(M \mathrm{~s}=.08, .77$, and
.00 , respectively), and narratives in the relational disequilibrium condition were most likely to exhibit excessive relational orientation $\left(M \mathrm{~s}=.04, .08\right.$, and .90 , respectively), $\chi^{2}(2, N=69)=27.24$, 39.31 , and 46.68 , respectively, all $p s<.01$. Thus, our manipulation appears to have been successful at eliciting the intended types of narrative.

Key dependent variables. As can be seen in Table 2, the effect of disequilibrium type was significant for all 10 dependent variables. Specifically, analyses examining motivation to restore equilibrium revealed that equilibrium narratives exhibited lesser selfreported desire to change, relational disequilibrium narratives exhibited greater desire for personal orientation, and personal disequilibrium narratives exhibited greater desire for relational orientation. Analyses of coders' ratings revealed parallel findings: Equilibrium narratives exhibited greater desire to maintain present circumstances, relational disequilibrium narratives exhibited greater desire for personal orientation, and personal disequilibrium narratives exhibited greater desire for relational orientation. That is, experiences of underdedication to the relational domain (personal disequilibrium) led to greater relational orientation and reduced personal orientation; experiences of overdedication to the relational domain (relational disequilibrium) led to greater personal orientation and reduced relational orientation. In addition, analyses examining both self-report measures and coders' ratings of life satisfaction revealed that equilibrium narratives exhibited greater self-reported life satisfaction and subjective well-being, along with greater coded satisfaction and lesser coded anxiety. These findings are consistent with model predictions, demonstrating that open-ended descriptions of prior disequilibrium experi- 
ences include evidence of desire to restore equilibrium, along with evidence of reduced life satisfaction and psychological well-being. Our confidence in these results is enhanced by the fact that parallel findings were evident in participants' self-report ratings of their experiences and in coders' ratings of participants' open-ended descriptions.

\section{Study 3}

The results of Studies 1 and 2 provide good support for our model, examining the impact of experimentally induced anticipation of disequilibrium, as well as narrative descriptions of prior disequilibrium experiences. These findings are consistent with the claim that when people anticipate or recall disequilibrium, they exhibit reduced well-being and increased motivation to restore equilibrium. At the same time, findings from these studies may have been colored by socially desirable responding or biased recall. When asked to recall a time when they felt "not at all immersed" or "too immersed," Study 2 participants may have reported on a specific subset of the full spectrum of possible equilibrium or disequilibrium experiences. For example, negative experiences of disequilibrium may have been more available and stereotype consistent than positive experiences. Moreover, Study 2 participants' narratives were solicited in the relational domain-in the context of underimmersion versus overimmersion in a close relationship. It is important to demonstrate that parallel results are evident when we study disequilibrium that is situated in the context of personal goal pursuits.

To address these limitations, we conducted Study 3, a diary study that examined experiences of disequilibrium in situ, during the course of everyday life (cf. Reis \& Wheeler, 1991). The diary technique is a useful means of studying disequilibrium in that it provides a window through which we can perceive disequilibrium in its natural context, without inducing the expectation of disequilibrium (as in Study 1) or explicitly calling to mind disequilibrium experiences (as in Study 2). The diary technique is also useful in that it allows us to examine the consequences of within-participant variation in disequilibrium or day-to-day fluctuations in equilibrium (e.g., for a given individual, how do experiences of equilibrium differ from experiences of disequilibrium?). Study 3 also complements Study 2 by examining experiences of disequilibrium that are situated in the context of everyday personal goal pursuits.

Participants in Study 3 took part in a 10-day study concerning their daily goal pursuits. Each evening, they completed diary records describing their level of dedication to the personal and relational domains, equilibrium in each domain (relative to the other domain), motivation to restore equilibrium, and life satisfaction. Our model implies three hypotheses (see Figure 2). First, we hypothesized that the experience of disequilibrium would promote motivation to restore equilibrium via enhanced motivation to the underdedicated domain and reduced motivation to the overdedicated domain. Second, we hypothesized that the experience of disequilibrium would predict behavior change toward restoring equilibrium via enhanced dedication to the underdedicated domain and reduced dedication to the overdedicated domain. Third, we hypothesized that the experience of disequilibrium would predict reduced life satisfaction.

\section{Method}

Participants. Participants were both partners from 92 couples (91 heterosexual couples, 1 lesbian couple) who resided in the Chapel Hill, NC, community. Participants were 22.07 years old on average $(S D=3.62)$, most were university students $(62 \%$ undergraduate students, $15 \%$ graduate students, $23 \%$ nonstudents), and most were Caucasian (15\% African American, 7\% Asian American, $72 \%$ Caucasian, $6 \%$ other). They had been involved with one another for an average of 22.31 months $(S D=18.24)$, and most were involved in steady dating relationships (91\% dating steadily, $6 \%$ engaged or married, $3 \%$ other).

Procedure. Participants were recruited through notices posted around the community and in local newspapers. They were informed that the study concerned the pursuit of personal life goals by partners in ongoing relationships. Participants were given packets including daily diary records, along with addressed, stamped envelopes for use in returning completed records to us. They were asked to complete a daily diary record each evening at about the same time describing their experiences during that day. If they were unable to complete the record on a given evening, they were asked to do so as soon as possible the next morning. Participants were asked not to speak with their partners about their records Completed diary records were returned to us following Days 4, 7, and 10. At the end of the 10-day period, participants completed an exit questionnaire that inquired about the reliability and validity of the data they provided (e.g., did they complete diary records each evening, were they actually romantically involved with the partners with whom they participated?). At the end of the study, participants were thoroughly debriefed, thanked for their assistance, and paid $\$ 60$ for taking part in the study.

Daily diary records. Items relevant to our model were distributed throughout the diary record form, interspersed with items designed to assess other constructs (e.g., behaviors enacted toward pursuit of the ideal self, partner support of individual goal pursuits). The records included one-item measures of personal disequilibrium level ("My personal needs interfered with the needs of my partner and relationship"; for all items, $1=$ do not agree at all, $5=$ agree completely) and relational disequilibrium level ("The needs of my partner and relationship interfered with my personal needs"). Motivation to restore equilibrium was assessed with one-item measures of desire for more personal orientation ("I intend to begin dedicating more time and effort to my personal needs") and desire for more relational orientation ("I intend to begin dedicating more time and effort to the needs of my partner and relationship"). Actual equilibrium restoration was assessed with one-item measures of personal dedication level ("Pursuing my goals was very important to me today"), and relational dedication level ("I tried to make sure my goal pursuits didn't pose any problems for my partner today"). A two-item measure of life satisfaction (e.g., "I was satisfied with my life today"; $\alpha=.85$ ) was also included. The observed daily levels of model variables were as we expected: Participants reported moderately low average levels of personal and relational disequilibrium $(M \mathrm{~s}=1.92$ and 1.79, $S D$ s $=1.15$ and 1.10 , respectively; range $=1-5$ ) and reported moderate to high levels of desire for personal and relational orientation, personal and relational dedication, and life satis- 
faction $(M$ s ranged from 3.20 to $3.94, S D$ s ranged from 0.91 to $1.23)$.

\section{Results and Discussion}

Data-analysis strategy. The data provided by a given individual across the 10 days of the study are not independent, and the data provided by the two partners in a given relationship are not independent. As such, the Study 3 design includes three levels of nesting in that the data from multiple diary reports are nested within individuals and the data from two individuals in a given relationship are nested within couple (Kenny, Kashy, \& Bolger, 1998). Therefore, we used hierarchical linear modeling to analyze our data (Raudenbush \& Bryk, 2002). This technique simultaneously examines lower level and upper level variance, thereby modeling each source of variance while accounting for statistical characteristics of the other level. Moreover, this technique is useful for a diary study in that it provides good estimates of model parameters even when there are missing data or differing numbers of assessment per participant (e.g., if diary records were not completed for 1 or more days).

We performed within-individual analyses wherein predictor variables were centered around each individual's mean across the 10 days. For example, a within-individual analysis might examine whether a given person experienced reduced life satisfaction on days when he or she experienced greater relational disequilibrium (relative to his or her mean level of relational disequilibrium across the 10 days). In addition, we performed analyses predicting both same-day criteria and next-day criteria. Analyses examining sameday criteria assessed residualized change, exploring concurrent associations of predictors with criteria, controlling for previousday levels of the criterion. For example, in predicting desire for more personal orientation from same-day personal or relational disequilibrium, we included as a covariate desire for more personal orientation level from the previous day. Analyses examining nextday criteria also assessed residualized change, exploring lagged associations of earlier predictors with later criteria, controlling for previous-day levels of the criterion. For example, in predicting relational dedication level from previous-day personal or relational disequilibrium, we included as a covariate relational dedication level from the previous day.

In Studies 1 and 2, we examined personal and relational disequilibrium as discrete phenomena: Participants were assigned to the personal or relational disequilibrium condition (or the equilibrium condition). In contrast, in Study 3, we measured personal and relational disequilibrium as independent constructs, such that on a given day, people might experience greater or lesser disequilibrium in either domain. To examine the unique variance attributable to each form of disequilibrium, in testing each hypothesis, we regressed each criterion simultaneously onto measures of personal disequilibrium and relational disequilibrium. In addition, to examine the unique variance attributable to a given criterion, we included as a covariate the criterion for the complementary construct. For example, in examining the predictors of personal dedication level, we controlled for relational dedication level.

We performed preliminary analyses to examine possible main effects of gender (in these analyses, variables were not centered around the individual's mean across the 10 days) and observed just

Table 3

Associations of Personal-Relational Disequilibrium and Personal-Relational Equilibrium-Restoration Motivation, With Key Criteria: Study 3

\begin{tabular}{|c|c|c|}
\hline Variable & $\beta$ & $t$ \\
\hline \multicolumn{3}{|l|}{ Motivation to restore equilibrium } \\
\hline \multicolumn{3}{|l|}{ Desire for more personal orientation from: } \\
\hline Same-day personal disequilibrium level & .01 & 0.17 \\
\hline Same-day relational disequilibrium level & .06 & $2.29^{*}$ \\
\hline \multicolumn{3}{|l|}{ Desire for more relational orientation from: } \\
\hline Same-day personal disequilibrium level & .06 & $2.47^{*}$ \\
\hline Same-day relational disequilibrium level & -.09 & $-4.83^{* *}$ \\
\hline \multicolumn{3}{|l|}{ Actual equilibrium restoration } \\
\hline \multicolumn{3}{|l|}{ Personal dedication level from: } \\
\hline Previous-day personal disequilibrium level & -.01 & -0.02 \\
\hline Previous-day relational disequilibrium level & .01 & 0.32 \\
\hline \multicolumn{3}{|l|}{ Relational dedication level from: } \\
\hline Previous-day personal disequilibrium level & .07 & $2.32^{*}$ \\
\hline Previous-day relational disequilibrium level & -.05 & $-1.87^{\dagger}$ \\
\hline \multicolumn{3}{|l|}{ Personal dedication level from: } \\
\hline Previous-day desire for more personal orientation & .06 & $2.21^{*}$ \\
\hline Previous-day desire for more relational orientation & .03 & 1.13 \\
\hline \multicolumn{3}{|l|}{ Relational dedication level from: } \\
\hline Previous-day desire for more personal orientation & -.06 & $-2.05^{*}$ \\
\hline Previous-day desire for more relational orientation & .01 & 0.42 \\
\hline
\end{tabular}

Life satisfaction

Same-day life satisfaction from:

Personal disequilibrium level

Relational disequilibrium level

$-.08-2.47^{*}$

$-.09-3.14^{* * *}$

Note. Personal disequilibrium $=$ overdedication to personal domain; relational disequilibrium $=$ overdedication to relational domain. All analyses are two-factor regression models; all analyses controlled for previousday levels of the criterion and for scores on the complementary criterion. Degrees of freedom for analyses with random slopes ranged from 1, 50 to 1,127 , and degrees of freedom for analyses with fixed slopes ranged from $(1,647)$ to $(1,836)$ (degrees of freedom varied across analyses because of missing data for some variables).

${ }^{\dagger} p<.10 .{ }^{*} p<.05 .^{* *} p<.01$.

one significant main effect of gender: Men reported slightly greater relational dedication than did women. To examine possible interactions with gender, we performed all analyses reported in Table 3, including gender terms, and observed one significant interaction. Given that gender typically did not moderate our findings, we dropped this factor from the analyses. We describe the one significant interaction effect below, in our review of Table 3 findings. 5

In addition, all analyses initially were performed representing both intercepts and slopes for key predictors as random effects, allowing Level 1 predictors to vary randomly across individuals and across couples. When tests examining the variance and covariance components revealed nonsignificant across-individual and across-couple differences in slopes, we recalculated models representing slopes as fixed effects. Earlier levels of criteria were

\footnotetext{
${ }^{5}$ We performed the gender-relevant analyses twice, once including and once excluding the lesbian couple. Hypothesis tests from the two sets of analyses revealed identical conclusions.
} 
represented as fixed effects to reduce potential multicolinearity among predictors and stabilize the iteration process (cf. S. L. Murray, Griffin, Rose, \& Bellavia, 2003). Discrepancies across analyses in degrees of freedom are attributable, in part, to missing data and, in part, to whether slopes were represented as fixed or random effects.

Usable versus unusable data. Although 184 individuals took part in the study (92 couples), we obtained usable data from a subset of 136 individuals because (a) 12 people failed to return their diary records despite repeated reminders, (b) 10 people (5 couples) admitted in exit questionnaires that they were not romantically involved (they took part to earn money), (c) 10 people admitted in exit questionnaires that their records were not particularly accurate, and (d) 16 people reported no personal or relational disequilibrium across the 10-day study. These 136 individuals completed nearly all of their interaction records $(68 \%$ completed all $10 ; M=9.41$ of $10, S D=1.01$ ). We performed preliminary analyses to determine whether participants with usable data differed from those with unusable data. First, we performed hierarchical linear modeling analyses to compare the two groups with respect to age, relationship duration, and daily scores for the seven variables listed in Table 3. Not surprisingly, the two groups differed in average levels of personal and relational disequilibrium: Levels of disequilibrium were lower among people with unusable data in that this group included 16 individuals who reported no disequilibrium across the 10-day study (both $p$ s $<$ $.01)$. The two groups did not differ with respect to any other variables (all $p s>.20$ ). Second, we replicated the analyses in Table 3, including data for people with both usable and unusable data (for the latter group, some data were missing or partial). In these analyses, one significant effect from Table 3 was reduced to marginal significance, but all other effects were identical in significance versus nonsignificance (and direction of association). Therefore, we excluded unusable data from our primary analyses.

Motivation to restore equilibrium. To test the hypothesis that disequilibrium predicts motivation to restore equilibrium, we examined the simultaneous associations of daily fluctuations in personal and relational disequilibrium with same-day desire for more personal orientation and same-day desire for more relational orientation. In each analysis, we controlled for previous-day levels of the criterion. In addition, to examine the unique associations of each type of disequilibrium with each criterion, in each analysis, we included as a covariate the measure of motivation to restore equilibrium in the complementary domain. As can be seen in Table 3 (Motivation to restore equilibrium section), disequilibrium significantly predicted restoration motivation in three cases out of four. Specifically, desire for more personal orientation was predicted by greater relational disequilibrium level (but not by personal disequilibrium level), and desire for more relational orientation was predicted by greater personal disequilibrium level and by lesser relational disequilibrium level. That is, experiencing overdedication to personal concerns (personal disequilibrium) is associated with increased relational motivation (i.e., desire for more relational orientation), and experiencing overdedication to relational concerns (relational disequilibrium) is associated with increased personal motivation (i.e., desire for more personal orientation) and reduced relational motivation.

Actual equilibrium restoration. To determine whether the experience of disequilibrium predicts actual changes in the amount of time and effort individuals dedicate to personal versus relational behaviors, we examined the simultaneous associations of daily fluctuations in personal and relational disequilibrium with nextday personal dedication level and next-day relational dedication level. We also performed parallel analyses in which we substituted measures of daily fluctuations in desire for more personal or relational orientation as predictor variables (in lieu of personal and relational disequilibrium). In each analysis, we controlled for previous-day levels of the criterion. To examine unique associations with each criterion, in each analysis, we included as a covariate the measure of dedication to the complementary domain. As can be seen in Table 3 (Actual equilibrium restoration section), significant or marginal prediction by previous-day experiences of personal and relational disequilibrium and previous-day desire for more personal or relational orientation were evident in four cases out of eight. For analyses predicting later behavior from earlier disequilibrium levels, we found that later personal dedication was not predicted by either previous-day personal or relational disequilibrium, but later relational dedication was predicted by both greater previous-day personal disequilibrium and lesser previousday relational disequilibrium. For analyses predicting later behavior from earlier experiences of desired personal and relational orientation, we found that later personal dedication level was predicted by greater previous-day desire for personal orientation and that later relational dedication level was predicted by lesser previous-day personal orientation; neither criterion was significantly predicted by previous-day relational orientation. ${ }^{6}$ Thus, next-day relational dedication level was fairly reliably predicted by earlier disequilibrium and desired orientation; parallel findings were less reliably observed for the prediction of next-day personal dedication level.

Life satisfaction. Finally, to determine whether the experience of disequilibrium predicts reduced life satisfaction, we examined the simultaneous associations of daily fluctuations in both personal and relational disequilibrium with same-day life satisfaction, controlling for previous-day levels of the criterion. As can be seen in Table 3 (Life satisfaction section), everyday life satisfaction was negatively associated with both personal and relational disequilibrium.

\section{Study 4}

The results of Studies 1 through 3 are consistent with the claim that when people anticipate or experience disequilibrium, they wish to restore equilibrium, exhibiting increased motivation toward the underdedicated domain, reduced motivation toward the complementary domain, or both. The results of Studies 2 and 3 are consistent with the claim that disequilibrium is associated with reduced life satisfaction. However, Study 2 findings regarding life satisfaction are based on retrospective reports, and Study 3 findings are limited to daily experiences of satisfaction. Do the benefits to life satisfaction of sustaining personal-relational equilibrium

\footnotetext{
${ }^{6}$ In predicting later relational dedication level, there was a significant interaction of gender with previous-day desire for relational orientation, $t(639)=2.70, p<.01$. Tests of simple effects revealed that this association was nonsignificant among men $(\beta=-.06), t(373)=-1.56, n s$, but significant among women $(\beta=.08), t(320)=2.08, p<.04$. Among women, earlier desire for more relational orientation was predictive of actual next-day increases in dedication to the relational domain.
} 
extend over relatively longer periods of time, and are such benefits evident for indices of well-being other than life satisfaction? In Study 4, we used data from a longitudinal study of ongoing relationships to examine the impact of personal-relational equilibrium on diverse indices of well-being over a 6-month period. We explored effects not only on life satisfaction per se but also on other indices of personal well-being (e.g., psychological adjustment, physical health), as well as relational well-being. In Study 4, we examined disequilibrium that was situated in a context in which both personal and relational concerns were salient in that it was a study of goal pursuits in the context of ongoing relationships.

\section{Method}

Participants. Participants were partners in 139 couples (135 heterosexual couples, 4 lesbian couples) who took part in Time 2 and Time 3 activities of a five-wave longitudinal study. At Time 2, participants were 26.07 years old on average $(S D=4.57)$. Their median personal income was $\$ 25,000$, nearly half of them were students (46\%), and most were Caucasian (7\% African American, $1 \%$ Asian American, 87\% Caucasian, 5\% other). They had been involved with one another for an average of 45.40 months $(S D=$ 24.05), and over half were married to one another (18\% dating steadily, $23 \%$ engaged, $53 \%$ married, $6 \%$ other).

Procedure. We recruited participants through notices posted around the community and in local newspapers. The requirement for participation was that couples be newly committed-at Time 1, they had begun living with one another, become engaged, or married one another within the previous year or planned to do so during the coming year. Couples took part in project activities once every 6 months. At Time 2, we mailed participants questionnaires that they returned to us in postage-paid, preaddressed envelopes. At Time 3, they participated in a laboratory session during which they completed questionnaires and engaged in activities unrelated to the present work. At the end of each research occasion, we partially debriefed couples, paid them, and thanked them for their assistance; they were fully debriefed at the end of Time 5 sessions. Couples received $\$ 50$ in payment at Time 2 and $\$ 60$ at Time 3.

Questionnaires. Instruments relevant to the present study were distributed throughout the questionnaires, interspersed with instruments that assessed other constructs (e.g., top six personal goals, partner affirmation of individual goal pursuits, commitment and trust levels, diverse traits). The Time 2 questionnaire included a measure of personal-relational equilibrium (two items; e.g., "I make both my relational needs and personal needs a major priority in life"; $0=d o$ not agree at all, $8=$ agree completely; $\alpha=.83$ ). To assess life satisfaction, at both Time 2 and Time 3, we included the measures of life satisfaction (Diener et al., 1985) and subjective well-being (Campbell et al., 1976) that were employed in Study 2 (Time $2 \alpha \mathrm{s}=$ .90 and .88; Time $3 \alpha \mathrm{s}=.89$ and .88). To assess psychological well-being, we included measures of depression and anxiety using subsets of Derogatis's (1994) Symptom Checklist-90-R; the depression subscale assessed the degree to which participants experienced each of 13 symptoms during the past 6 months (e.g., "loss of sexual interest or pleasure"; Time 2 and $3 \alpha \mathrm{s}=.92$ and .90 , respectively), and the anxiety subscale assessed the degree to which participants experienced each of 10 symptoms during the past 6 months (e.g., "nervousness or shakiness inside"; for both instruments, $0=$ not at all, $8=$ extremely; Time 2 and $3 \alpha \mathrm{s}=.88$ and .89 , respectively). We assessed physical well-being using Cohen and Hoberman's (1983) Physical Health Checklist, in which participants reported whether they had experienced each of 33 symptoms over the past 6 months (e.g., migraine headaches, cold and coughs, stomach pain; Time 2 and $3 \alpha \mathrm{s}=.83$ and .82 , respectively). We reverse coded the items to reflect physical health as the absence of physical symptoms. We assessed relational well-being using a 30-item version of the Dyadic Adjustment Scale that is suitable for both cohabiting and noncohabiting couples; the scale taps components of functioning, such as agreement regarding values (religion, career decisions), conflict management, shared activities, and expressions of love (Spanier, 1976; e.g., "Do you confide in your partner?"; $0=$ never, $5=$ all the time; Time 2 and $3 \alpha \mathrm{s}=.91$ and .90 , respectively). Finally, to control for socially desirable response tendencies, at Time 3 , we also included a 10-item self-deception subscale and a 10-item impressionmanagement subscale from Paulhus' (1984) Socially Desirable Responding Scale (e.g., "I have not always been honest with myself"; $1=$ do not agree at all, $7=$ agree completely $\alpha \mathrm{s}=.70$ and .70 , respectively).

\section{Results}

Data-analysis strategy. We used hierarchical linear modeling to analyze our data in that the data from two individuals in a given relationship are nested within couple (Raudenbush \& Bryk, 2002). We performed residualized lagged analyses, predicting Time 3 criteria from Time 2 predictor variables, controlling for Time 2 measures of the criterion. All analyses were initially performed including main effects and interactions for participant gender. These analyses revealed three main effects of gender (women reported marginally greater depression, greater anxiety, and greater couple well-being than did men) but no interactions of gender with other variables. Therefore, gender effects are not discussed below.

All analyses initially were performed representing both intercepts and slopes as random effects, allowing Level 1 predictors to vary randomly across individuals and across couples. When tests examining the variance and covariance components in these analyses revealed nonsignificant across-couple differences in slopes, we recalculated models representing slopes as fixed effects. We represented earlier levels of criteria as fixed effects to reduce potential multicolinearity among predictors and to stabilize the iteration process (cf. S. L. Murray et al., 2003).

Predicting life satisfaction and well-being. As can be seen in Table 4, in predicting criteria 6 months later-and controlling for earlier levels of each criterion-earlier personal-relational equilibrium is positively associated with life satisfaction, physical well-being, and relational well-being; marginally positively associated with subjective well-being; and significantly negatively associated with depression and anxiety. ${ }^{7}$ When measures of socially desirable response tendencies and impression management were included in the analyses, all effects for personal-relational equilibrium remained significant or marginally significant; that is, these associations were evident beyond any variance attributable to socially desirable responding. Thus, over a relatively prolonged

\footnotetext{
${ }^{7}$ We performed these analyses twice, once including and once excluding data for the four lesbian couples. In five of the six analyses in which we excluded data for lesbian couples, earlier personal-relational equilibrium accounted for significant or marginal variance in Time 3 criteria.
} 
period of time, maintaining equilibrium between one's personal and relational concerns is beneficial not only to life satisfaction but also to psychological well-being, physical health, and the wellbeing of one's relationship.

\section{General Discussion}

Personal concerns and relational concerns are two fundamental human motives. Whereas these two classes of concern can often be pursued and gratified simultaneously, these motives sometimes compete for limited time, energy, or other resources. Thus, dedication to one domain sometimes comes at the expense of the other. The present research advanced a model of personal-relational equilibrium, proposing that humans are motivated to maintain equilibrium between personal and relational concerns. We examined two central features of the model: First, we proposed that, as people dedicate increased time and effort to a given concern at the expense of concerns in the complementary domain, their motivation toward the underdedicated domain increases, and their motivation toward the overdedicated domain declines. Second, we proposed that disequilibrium yields reduced life satisfaction and well-being.

\section{Motivation to Restore Optimal Equilibrium}

When people experience disequilibrium between their personal and relational concerns, are they motivated to restore optimal equilibrium? In Study 1, we employed an experimental manipulation to assess whether disequilibrium exerts causal effects on motivation. As predicted, when people anticipated that they would experience future personal disequilibrium, they exhibited increased relational motivation (greater willingness to sacrifice, inclusion of partner in the self) and reduced personal motivation (reduced personal goal-pursuit motivation); when people anticipated future relational disequilibrium, they exhibited increased personal motivation and reduced relational motivation. Study 2

\section{Table 4}

Associations of Personal-Relational Equilibrium With Key Criteria: Study 4

\begin{tabular}{lcc}
\hline Variable & $\beta$ & $t$ \\
\hline $\begin{array}{l}\text { Later life satisfaction } \\
\quad \text { from earlier personal-relational equilibrium level }\end{array}$ & .11 & $2.28^{* *}$ \\
$\begin{array}{l}\text { Later subjective well-being } \\
\quad \text { from earlier personal-relational equilibrium level }\end{array}$ & .11 & $1.89 \dagger$ \\
$\quad \begin{array}{l}\text { Later depression } \\
\quad \text { from earlier personal-relational equilibrium level }\end{array}$ & -.12 & $-2.35^{*}$ \\
$\quad \begin{array}{l}\text { Later anxiety } \\
\quad \text { from earlier personal-relational equilibrium level }\end{array}$ & -.16 & $-2.46^{*}$ \\
$\quad \begin{array}{l}\text { Later physical well-being } \\
\quad \text { from earlier personal-relational equilibrium level }\end{array}$ & .14 & $3.18^{* *}$ \\
$\quad \begin{array}{l}\text { Later relational well-being } \\
\quad \text { rrom earlier personal-relational equilibrium level }\end{array}$ & .17 & $3.91^{* *}$ \\
\hline
\end{tabular}

Note. All predictor variables are Time 2 measures, all criteria are Time 3 measures, and all analyses controlled for Time 2 levels of the criterion. Degrees of freedom for analyses with random slopes $=1,111$, and degrees of freedom for analyses with fixed slopes ranged from $(1,128)$ to $(1,129)$ (degrees of freedom varied across analyses because of missing data for some variables).

${ }^{\dagger} p<.10 .{ }^{*} p<.05$. $^{* *} p<.01$. extended these findings, demonstrating that for both self-report and trained coders' ratings of open-ended, narrative accounts of previous life experiences, narratives describing disequilibrium experiences were characterized by increased motivation toward the underdedicated domain and decreased motivation toward the overdedicated domain; narratives describing equilibrium experiences exhibited comfort with present circumstances and little or no desire for change in dedication.

In Study 3, we employed a daily diary method to examine equilibrium seeking over the course of a 10-day period. As predicted, on days when people experienced disequilibrium in either the personal or relational domain, they exhibited enhanced motivation toward the underdedicated domain. We also observed some evidence that disequilibrium motivates reduced attention to the overdedicated domain - on days when people experienced relational disequilibrium, they were motivated to turn their attention away from the relational domain (the parallel effect was not significant for personal disequilibrium). These findings are particularly striking in that these analyses (a) examined within-person variation in disequilibrium, wherein predictor variables were centered around each person's mean across the 10 days, and (b) controlled both for previous-day levels of the criterion and for same-day scores on the complementary criterion.

Study 3 findings regarding actual next-day equilibrium restoration suggest that there may be an asymmetry in behaviors oriented toward restoring optimal equilibrium. The analyses revealed that (a) as predictor variables, the association of earlier disequilibrium experiences (and motivation to restore equilibrium) with next-day behavior was descriptively stronger for personal disequilibrium than for relational disequilibrium (average absolute $\beta \mathrm{s}=.05$ vs. .02 ), whereas (b) as criteria, the associations with next-day change were descriptively stronger for relational dedication level than for personal dedication level (average absolute $\beta s=.06$ vs. .01). These findings suggest that people may be less tolerant of personal disequilibrium (i.e., more intent on addressing personal disequilibrium problems) and more flexible with respect to modifying relational dedication level (i.e., more willing to change behavior in the relational domain). Such findings may stand as evidence for the primacy of the personal domain over the relational domain (Gaertner, Sedikides, \& Graetz, 1999)—-that is, people may place greater emphasis on their personal needs than on their relational needs such that when push comes to shove, personal needs receive priority. ${ }^{8}$ However, we should exercise caution in interpreting Study 3 findings in that (a) this theoretical analysis is post hoc, and other interpretations are possible; (b) Study 3 diary records were situated in a personal context (in a project regarding personal goal pursuits) such that personal concerns may have been weighted somewhat more heavily; (c) $75 \%$ of the participants were under-

\footnotetext{
${ }^{8}$ In Study 2, personal and relational disequilibrium narratives exhibited approximate symmetry in their effects on motivation. However, to the extent that they departed from symmetry, personal needs may have received priority - for example, in manipulation-check ratings of the extent to which the disequilibrium conditions exhibited excessive levels of one or the other concern, coders judged that relational disequilibrium narratives were more excessively relational (.90 [vs. .04 and .08 in other conditions]) than personal disequilibrium narratives were excessively personal (.50 [vs. .00 and .00 in other conditions]) - that is, personal disequilibrium was judged to be less excessive.
} 
graduates or graduate students, who may be more likely to face pressing and inflexible personal deadlines; and (d) this research was conducted in a relatively individualistic culture, where people may place relatively greater emphasis on personal concernsfindings regarding equilibrium restoration might differ for individuals who place a higher priority on relational concerns, such as couples with children or people from collectivistic cultures (cf. Markus \& Kitayama, 1991). Moreover, findings regarding personal and relational disequilibrium tended to be relatively symmetric in Studies 1 and 2. Thus, this issue merits further attention in future research.

\section{Life Satisfaction and Well-Being}

The present research also revealed good support for the claim that when people experience disequilibrium between their personal and relational concerns, they suffer reduced life satisfaction. In analyses performed on Study 2 narrative accounts, findings based on both self-report ratings and coders' ratings revealed that people experienced greater life satisfaction during periods of equilibrium than during periods of either personal disequilibrium or relational disequilibrium. Findings from Study 3 daily diary reports corroborate these results, revealing that on days when people experienced greater equilibrium, they also experienced greater life satisfaction (controlling for previous-day satisfaction). Findings from Study 4 revealed that the benefits of maintaining equilibrium were evident 6 months later (controlling for well-being 6 months earlier) not only for global life satisfaction and subjective well-being but also for psychological adjustment (low depression and anxiety), physical health, and relational well-being. Findings for relational wellbeing are particularly noteworthy, given that, a priori, overdedication to relational concerns at the expense of personal concerns might be expected to benefit relationships. However-and consistent with predictions - it appears that relationships function best when partners sustain a desired equilibrium between personal and relational domains. That is, relational well-being, too, is optimized to the extent that people (a) engage in activities that simultaneously gratify the two domains and/or (b) exhibit relatively efficient temporal shifts from one domain to the other.

These findings illustrate the powerful impact of equilibrium on both immediate and prolonged well-being - not only for life satisfaction and subjective well-being but also for psychological adjustment, physical health, and couple adjustment—and are consistent with the claim that maintaining equilibrium indeed contributes to a meaningful life. In future research, it will be important to examine the precise basis for the harmful effects of disequilibrium: Is personal-relational disequilibrium harmful primarily because it represents neglect of one or the other class of concern or primarily because the accompanying aversive motivational state takes its toll? It is even possible that disequilibrium is problematic because it takes time, effort, and resources away from other, potentially more gratifying activities in both the personal and relational domains or because people must apply self-regulatory resources to restore equilibrium such that disequilibrium causes ego depletion (Baumeister, Bratslavsky, Muraven, \& Tice, 1998; Finkel \& Campbell, 2001).

\section{Broader Implications}

Our work examines the interplay of personal and relational concerns. Granted, these are not the only sources of meaning in life. But at the same time, it is not unreasonable to suggest that personal and relational concerns are among the most fundamental components of human motivation. Personality theorists have traditionally argued for the centrality of personal and relational concerns (e.g., Bakan, 1966; Freud, 1920; Maslow, 1968), and many contemporary researchers have addressed the difficulty of simultaneously gratifying the two domains, examining the needs for autonomy versus interdependence or affiliation versus solitude (e.g., Altman, Vinsel, \& Brown, 1981; O'Connor \& Rosenblood, 1996). Building on homeostasis theory (Cannon, 1920), the present work offers evidence of a tendency to seek equilibrium with respect to personal and relational concerns. Future work may demonstrate that limited time, effort, and resources also cause people to seek equilibrium with respect to other potentially conflicting life domains, such as the needs of the self in relation to the needs of the collective.

Our work thus complements and extends existing theories of motivation and is consistent with the claim that humans seek to gratify not only personal needs but also relational needs (e.g., Deci \& Ryan, 2000; Ryff, 1989). This work also extends prior research regarding the importance of balance in the gratification of diverse needs (Sheldon \& Niemiec, 2006), including prior findings regarding the liabilities of work-family conflict and caregiver-role conflict (e.g., Adams et al., 1996; Grant-Vallone \& Donaldson, 2001; Stephens \& Franks, 1999). We have argued that our personalrelational equilibrium model helps to explain such findings, but might our results alternatively be explained by a straightforward need-fulfillment model? For example, when people experience a deficit in relational gratification, they seek increased fulfillment in that domain; when they experience a deficit in personal gratification, they seek increased fulfillment in that domain. Indeed, the equilibrium process clearly rests on the assumption that people behave in such a manner as to gratify important needs. But whereas a straightforward need-fulfillment model readily predicts increased dedication of resources to a presently underdedicated domain (i.e., going for what one is presently not getting), it does not readily account for decreased dedication to a presently overdedicated domain (i.e., going away from what one is presently getting). We believe that our model complements and extends existing need-fulfillment models by identifying an adaptationbased self-regulatory tendency toward equilibrium — an adaptation that allows for maximal need fulfillment in light of finite resources.

Might our results alternatively be explained by a dialectical model? A dialectical model might suggest that personal and relational needs represent equal and opposing forces, that over time people oscillate between these two forces, and that optimal functioning is evident when one's current state matches one's ideal state. Thus, if Mary wants to pursue her relational needs but cannot to do so because of pressing work demands, both models would predict that she would exhibit increased relational motivation. Indeed, the process we have identified could suitably be described as dialectical among people for whom personal and relational concerns are thoroughly distinct, or in situations in which very few activities can simultaneously gratify the two domains. However, 
whereas a dialectical model would suggest that individuals naturally and invariably oscillate between complementary domains, our model suggests that an individual may be content to remain in a present state so long as it lies within his or her optimal equilibrium region. Moreover, we believe that our equilibrium model better represents the character of everyday life in that personal and relational concerns are not necessarily incompatible- often, people can simply, harmoniously, and simultaneously gratify both classes of need.

The clinical implications of these findings are self-evident, especially in regard to psychological, physical, and relational well-being. It becomes particularly important to advance understanding of personal-relational equilibrium as people's lives become increasingly complex and as it becomes increasingly difficult to sustain equilibrium across complementary domains. Our findings demonstrate that people regulate their behavior not only in response to present disequilibrium but also in anticipation of future disequilibrium. Disequilibrium has both immediate and long-term consequences for life satisfaction and affects not only personal well-being but also long-term couple functioning. Thus, the ability to successfully regulate the time, effort, and resources that we dedicate to gratifying both sources of concern has profound implications for what it means to lead a meaningful life. As such, it is important to understand the underlying source of motivation and the consequences of the ability (vs. inability) to maintain equilibrium. It is interesting that some authors have speculated that the difficulty of sustaining a balance of personal and relational concerns may contribute to declining birthrates, as well as to delay (or avoidance) of marriage among women, particularly in societies with traditional gender-role attitudes-for example, well-educated women in traditional societies may opt to forego otherwise attractive relational experiences as a means of avoiding the chronic disequilibrium that such experiences would induce (e.g., McDonald, 1997; Ono, 2003).

Finally, the present work examined the validity of the equilibrium model in the context of ongoing romantic relationships, not with respect to other relational concerns, such as the concerns involved in parenting or in sustaining long-term friendships or collegial relationships. Romantic relationships are one of the most interdependent types of relationship, one in which there are powerful demands for coordinating personal concerns relative to relational concerns. At the same time, we believe that the principles of our equilibrium model will generalize to other types of relationship, and we suggest that it will be important to examine other contexts in which people experience tension between satisfying their personal and relational needs. For example, it might be interesting to examine parent-child relationships, wherein parents cannot set aside the crucial needs of their children yet continue to have personal needs, the pursuit of which may conflict with gratifying the needs of their children.

\section{Strengths, Limitations, and Directions for Future Research}

It is important to note several strengths and limitations of this work, beginning with the latter. First, might our findings be attributable to demand characteristics or socially desirable responding? Is it possible that disequilibrium does not actually exert deleterious effects or induce motivational shifts-is it possible that people simply "fake bad" in response to disequilibrium situations on the basis of their belief that equilibrium is good? We think not in that in Study 1, we observed parallel results even when we excluded data for participants who expressed suspicion; in Study 2, we emphasized that immersion level was not necessarily indicative of health or well-being; and in Study 4, we statistically controlled for individual tendencies toward self-deception and impression management. Moreover, in Studies 3 and 4, equilibrium-relevant items were imbedded in diary reports and in questionnaires that concerned unrelated phenomena. Finally, the analysis strategies in Studies 3 and 4 were relatively challenging in that they controlled for earlier measures of criteria (both studies), examined withinperson variability in predictors (Study 3), and/or examined changes in criteria over a 6-month period of time (Study 4). At the same time, future work should seek to test the personal-relational equilibrium model employing even more subtle and indirect methods-for example, via nonconscious priming of disequilibrium or measurement of motivation using a lexical decision task.

Second, in Study 3, we discovered that the reliable effects we observed for motivation to restore equilibrium were not so reliably observed for actual equilibrium restoration, at least insofar as it was manifested in reports of next-day changes in behavior. In future work, it will be important to study the temporal patterning of self-regulatory acts aimed toward equilibrium restoration, allowing for the possibility that disequilibrium may exist for days, weeks, or months before people find the wherewithal to restore equilibrium. People may not always be aware of the existence of disequilibrium, and external forces may make it difficult or impossible to restore equilibrium. Moreover, there may be circumstances in which people are not particularly dissatisfied with disequilibrium (i.e., equilibrium standards may change)—for example, parents may not feel unhappy about complete absorption in their newborn child, and scientists may not feel unhappy about complete absorption in the analysis of new data. People may even sustain disequilibrium as a means of avoiding unwanted experiences or outcomes in the underdedicated domain (e.g., living with personal disequilibrium because one wishes to avoid facing the deterioration of one's marriage). Thus, future work should assess whether equilibrium restoration necessarily rests on awareness of disequilibrium and should explore the dispositional and situational factors that may moderate tolerance of disequilibrium.

Third, we believe that future research might benefit from a differentiated examination of states of disequilibrium. For example, personal disequilibrium that is attributable to a pressing deadline at work may yield different dynamics than personal disequilibrium that is attributable to indifference to a partner or to avoidant attachment tendencies. And relational disequilibrium that is attributable to fear of losing a partner may yield different dynamics than relational disequilibrium that is attributable to passionate absorption in a new relationship. Also, given that people sometimes dedicate time to important yet unpleasant activities (e.g., housecleaning, doing the taxes), it might be interesting to examine possible differences between disequilibrium processes that rest on inherently rewarding versus costly behaviors. Moreover, although our work examines the motivation to maintain and restore equilibrium as a within-individual process, disequilibrium may often have interpersonal origins. For example, John's illness or job loss may require that Mary place relational needs first, or Mary's absence during a business trip may create opportunities for John to focus more exclusively on his personal needs. Moreover, the process of equilibrium restoration may also be interpersonal. For example, a 
partner might exacerbate disequilibrium-based tension by demanding a reduction in one's work hours or might ameliorate tension by contributing a greater share to the household labor. Thus, we believe that the interpersonal causes and consequences of intrapersonal equilibrium seeking merit further attention.

Fourth, future research should examine more diverse samples of participants to assess the generalizability of the present findings. For example, balancing personal and relational needs is frequently regarded as a greater concern for women than for men. Our studies revealed very little evidence of substantively meaningful gender differences in equilibrium seeking or in the association of equilibrium with well-being. The only instance in which we observed significant moderation by gender was in Study 3, in which women were more likely than men to increase next-day dedication to the relational domain as a result of strong motivation to restore relational equilibrium. At the same time, such differences might be evident in older populations or in populations including a greater proportion of participants with careers or with children. Moreover, research examining cross-cultural differences suggests that people in Western cultures are more likely than their counterparts in collectivistic cultures to be focused on individual needs, sometimes at the expense of the needs of their relationships or social groups (e.g., Markus \& Kitayama, 1991). Future research should examine whether individualistic versus collectivistic orientation influences equilibrium processes.

Finally, in future work, it will be important to study the origins and character of optimal equilibrium standards. We suspect that such work might be a particularly fruitful means of understanding possible gender and cultural differences in the experience of disequilibrium. On the basis of the present work, we do not know whether men and women (or people from differing cultures) possess identical optimal regions in that we did not manipulate or measure optimal standards - we employed operational definitions that implicitly calibrate equilibrium versus disequilibrium relative to a given participant's subjective sense of what is optimal (see footnote 4). Future research should examine whether optimal standards vary with respect to the dimensions we identified earlier and should determine whether there are meaningful individual differences or situational influences on the character of optimal standards. In the preliminary research that we have conducted to date, it appears that (a) on average, people's optimal regions are centered on approximately equal dedication to personal and relational concerns; (b) people prefer equilibrium that is achieved through moderate dedication to both personal and relational concerns (exceptionally low dedication to both domains and exceptionally high dedication to both domains appear to be undesirable); and (c) there are no striking gender differences in preferences $(\mathrm{Ku}-$ mashiro, Rusbult, \& Finkel, 2007).

We close with a review of what we regard as strengths of this work: To our knowledge, this is the first work to examine both (a) the underlying dynamics of equilibrium, or the intrapersonal motivation to gratify both personal and relational concerns, and (b) the consequences of equilibrium versus disequilibrium for wellbeing. Across the four studies, we examined diverse aspects of disequilibrium, including reactions to actual experiences of disequilibrium, responses to anticipated future disequilibrium, the consequences of everyday interference with needs in one domain by needs in the other, and tendencies to dedicate commensurate time and effort to the two domains. Across studies, we examined disequilibrium experiences that were situated in both personal and relational contexts: In Study 2, we examined disequilibrium in the context of under- versus overimmersion in a relationship, whereas in Study 3, we examined disequilibrium in the context of individuals' everyday goal pursuits. We also allowed for diversity across individuals in optimal standards. For example, in Study 2, we examined narrative descriptions of equilibrium versus disequilibrium as experienced by participants themselves, and in Study 3, we examined within-person effects, exploring the motivational and behavioral effects of day-to-day variations in equilibrium versus disequilibrium within a given individual. Moreover, we examined the short-term and long-term consequences of disequilibrium not only for motivation and behavior but also for well-being. Finally, we obtained converging evidence of equilibrium-seeking using diverse methods and measurement techniques, thereby helping to rule out alternative explanations of our findings, such as biased recall, demand characteristics, or socially desirable responding.

\section{Conclusions}

The present program of research addresses the delicate interplay between two of the most fundamental and powerful sources of human concern: personal and relational. As an integral aspect of human existence, people dedicate much of their energy and resources toward finding, building, and maintaining relationships that fulfill many of the most basic of human needs. At the same time, relational needs are not invariably in harmony with personal needs. To the extent that the pursuit of one class of concerns detracts from the complementary concern, people experience tension and exhibit temporal shifts in their dedication to personal versus relational concerns in such a manner as to sustain equilibrium. Moreover, the inability to sustain equilibrium manifests itself in poor outcomes, such as impaired psychological functioning and reduced couple well-being. We hope that increased insight into this source of tension may enhance our broader knowledge of the character of self-regulation and the sources of fulfillment and vitality in life.

\section{References}

Adams, G. A., King, L. A., \& King, D. W. (1996). Relationship of job and family involvement, family social support, and work-family conflict with job and life satisfaction. Journal of Applied Psychology, 81, 411-420.

Altman, I., Vinsel, A., \& Brown, B. B. (1981). Dialectic conceptions in social psychology: An application to social penetration and privacy regulation. In L. Berkowitz (Ed.), Advances in experimental social psychology (Vol. 14, pp. 107-160). New York: Academic Press.

Aron, A., \& Aron, E. (2000). Self-expansion motivation and including other in the self. In W. Ickes \& S. Duck (Eds.), The social psychology of personal relationships (pp. 109-128). New York: Wiley.

Aron, A., Aron, E., \& Smollan, D. (1992). Inclusion of Other in the Self Scale and the structure of interpersonal closeness. Journal of Personality and Social Psychology, 63, 596-612.

Bakan, D. (1966). The duality of human existence: An essay on psychology and religion. Chicago: Rand McNally.

Baumeister, R. F., Bratslavsky, E., Muraven, M., \& Tice, D. M. (1998). Ego depletion: Is the active self a limited resource? Journal of Personality and Social Psychology, 74, 1252-1265.

Baumeister, R. F., \& Leary, M. R. (1995). The need to belong: Desire for interpersonal attachments as a fundamental human motivation. Psychological Bulletin, 117, 497-529.

Baumeister, R. F., Stillwell, A. M., \& Wotman, S. R. (1990). Victim and perpetrator accounts of interpersonal conflict: Autobiographical narra- 
tives about anger. Journal of Personality and Social Psychology, 59, 994-1005.

Berkman, L. F., Leo-Summers, L., \& Horwitz, R. I. (1992). Emotional support and survival after myocardial infarction: A prospective, population-based study of the elderly. Annals of Internal Medicine, 117, 1003-1009.

Bowlby, J. (1969). Attachment and loss: Vol. 1. Attachment. New York: Basic Books.

Campbell, A., Converse, P. E., \& Rodgers, W. L. (1976). The quality of American life: Perceptions, evaluations, and satisfactions. New York: Russell Sage Foundation.

Cannon, W. B. (1920). Bodily changes in pain, hunger, fear and rage: An account of recent researches into the function of emotional excitement. New York: Appleton.

Carver, C. S., \& Scheier, M. F. (1998). On the self-regulation of behavior. New York: Cambridge University Press.

Cohen, S., \& Hoberman, H. M. (1983). Positive events and social supports as buffers of life change stress. Journal of Applied Social Psychology, 13, 99-125.

Deci, E. L., La Guardia, J. G., Moller, A. C., Scheiner, M. J., \& Ryan, R. M. (2006). On the benefits of giving as well as receiving autonomy support: Mutuality in close friendships. Personality and Social Psychology Bulletin, 32, 313-327.

Deci, E. L., \& Ryan, R. M. (2000). The "what" and "why" of goal pursuits: Human needs and the self-determination of behavior. Psychological Inquiry, 11, 227-268.

Derogatis, L. R. (1994). SCL-90-R: Symptom Checklist-90-R: Administration, scoring, and procedures manual (3rd Ed.). Minneapolis, MN: National Computer Systems.

Diener, E., Emmons, R. A., Larsen, R. J., \& Griffin, S. (1985). The Satisfaction With Life Scale. Journal of Personality Assessment, 49, 71-75.

Drigotas, S. M., Rusbult, C. E., Wieselquist, J., \& Whitton, S. (1999). Close partner as sculptor of the ideal self: Behavioral affirmation and the Michelangelo phenomenon. Journal of Personality and Social Psychology, 77, 293-323.

Erikson, E. H. (1950). Childhood and society (2nd ed.). Oxford, England: Norton.

Finkel, E. J., \& Campbell, W. K. (2001). Self-control and accommodation in close relationships: An interdependence analysis. Journal of Personality and Social Psychology, 81, 263-277.

Freud, S. (1920). Beyond the pleasure principle. In J. Strachey (Ed.), The standard edition of the complete psychological works of Sigmund Freud (Vol. 18, pp. 7-64). London: Hogarth Press. (Original work published 1955)

Gaertner, L., Sedikides, C., \& Graetz, K. (1999). In search of selfdefinition: Motivational primacy of the individual self, motivational primacy of the collective self, or contextual primacy? Journal of Personality and Social Psychology, 76, 5-18.

Grant-Vallone, E. J., \& Donaldson, S. I. (2001). Consequences of workfamily conflict on employee well-being over time. Work and Stress, 15, 214-226.

Hazan, C., \& Shaver, P. R. (1994). Attachment as an organizational framework for research on close relationships. Psychological Inquiry, 5, 1-22.

Kelley, H. H., Holmes, J. G., Kerr, N. L., Reis, H. T., Rusbult, C. E., \& Van Lange, P. A. M. (2003). An atlas of interpersonal situations. New York: Cambridge University Press.

Kenny, D. A., Kashy, D. A., \& Bolger, N. (1998). Data analysis in social psychology. In D. T. Gilbert, S. T. Fiske, \& G. Lindzey (Eds.), Handbook of social psychology (4th ed., Vol. 1, pp. 233-265). Boston: McGraw-Hill.

Kumashiro, M., Rusbult, C. E., \& Finkel, E. J. (2007). The character and dynamics of optimal personal-relational equilibrium standards. Unpublished manuscript, University of Hamburg, Hamburg, Germany.

Marks, S. R. (1977). Multiple roles and role strain: Some notes on human energy, time, and commitment. American Sociological Review, 42, 921-936.
Markus, H., \& Kitayama, S. (1991). Culture and the self: Implications for cognition, emotion, and motivation. Psychological Review, 98, 224-253.

Maslow, A. H. (1968). Toward a psychology of being (2nd ed.). New York: Van Nostrand Reinhold.

McDonald, P. (1997). Gender equity, social institutions, and the future of fertility. In M. E. Cosio-Zavala (Ed.), Women and families: Evolution of the status of women as factor and consequences of changes in family dynamics (pp. 13-33). Paris: Cicred.

McEwen, B. S. (1998). Protective and damaging effects of stress mediators. Seminars in Medicine of the Beth Israel Deaconess Medical Center. $338,171-179$.

Murray, H. A. (1938). Explorations in personality. New York: Oxford University Press.

Murray, S. L., Griffin, D. W., Rose, P., \& Bellavia, G. M. (2003). Calibrating the sociometer: The relational contingencies of self-esteem. Journal of Personality and Social Psychology, 85, 63-84.

Myers, D. G., \& Diener, E. (1995). Who is happy? Psychological Science, 6, 10-19.

O'Connor, S. C., \& Rosenblood, L. K. (1996). Affiliation motivation in everyday experience: A theoretical comparison. Journal of Personality and Social Psychology, 70, 513-522.

Ono, H. (2003). Women's economic standing, marriage timing, and crossnational contexts of gender. Journal of Marriage and the Family, 65, 275-286.

Paulhus, D. L. (1984). Two-component models of socially desirable responding. Journal of Personality and Social Psychology, 46, 598-609.

Raudenbush, S. W., \& Bryk, A. S. (2002). Hierarchical linear models: Applications and data analysis methods. Thousand Oaks, CA: Sage.

Reis, H. T., \& Wheeler, L. (1991). Studying social interaction with the Rochester Interaction Record. In M. P. Zanna (Ed.), Advances in experimental social psychology (Vol. 24, pp. 269-318). New York: Academic Press.

Rusbult, C. E., Kumashiro, M., Coolsen, M., \& Kirchner, J. (2004). Interdependence, closeness, and relationships. In D. Mashek \& A. Aron (Eds.), The handbook of closeness and intimacy (pp. 137-161). Mahwah, NJ: Erlbaum.

Ryff, C. D. (1989). Happiness is everything, or is it? Explorations on the meaning of psychological well-being. Journal of Personality and Social Psychology, 57, 1069-1081.

Sheldon, K. M., \& Niemiec, C. P. (2006). It's not just the amount that counts: Balanced need satisfaction also affects well-being. Journal of Personality and Social Psychology, 91, 331-341.

Spanier, G. B. (1976). Measuring dyadic adjustment: New scales for assessing the quality of marriage and similar dyads. Journal of Marriage and the Family, 38, 15-28.

Stagner, R. (1951). Homeostasis as a unifying concept in personality theory. Psychological Review, 58, 5-17.

Stephens, M. A. P., \& Franks, M. M. (1999). Parent care in the context of women's multiple roles. Current Directions in Psychological Science, 8, $149-152$.

Twenge, J. M., Catanese, K. R., \& Baumeister, R. F. (2002). Social exclusion causes self-defeating behavior. Journal of Personality and Social Psychology, 83, 606-615.

Uchino, B. N., Cacioppo, J. T., \& Kiecolt-Glaser, J. K. (1996). The relationship between social support and physiological processes: A review with emphasis on underlying mechanisms and implications for health. Psychological Bulletin, 119, 488-531.

Van Lange, P. A. M., Rusbult, C. E., Drigotas, S. M., Arriaga, X. B., Witcher, B. S., \& Cox, C. L. (1997). Willingness to sacrifice in close relationships Journal of Personality and Social Psychology, 72, 1373-1395.

Received August 23, 2006

Revision received September 28, 2007 Accepted September 30, 2007 